\title{
Evaluation of Community Pharmacies Dispensing Pattern and Practice of Antituberculosis Drugs in North Karnataka Region
}

\author{
Uday Kumar Rangaswamy*, Madiwalayya Shivakantayya Ganachari \\ Department of Pharmacy Practice, KLE College of Pharmacy, KLE Academy of Higher Education and Research, Belagavi, Karnataka, INDIA.
}

\begin{abstract}
Objectives: The study aimed to evaluate the dispensing pattern and practices of community pharmacies towards antituberculosis drugs. Materials and Methods: A cross sectional, prospective study was conducted at Belagavi, Karnataka, India based on survey of pharmaceutical outlets in the locality. A structured interview form was used to assess availability and non-availability of Anti-TB drugs, dispensing Anti-TB drugs, Community pharmacist dispensing pattern of Anti-TB drugs in weekly and monthly basis. Results: A total of 228 community pharmacists participated in the Survey. Of these, 204 community pharmacists $(90.35 \%)$ were male and 22 community pharmacists (9.65\%) were female. The majority of 198 community pharmacists $(86.84 \%)$ Diploma in Pharmacy (D. Pharm). 86 community pharmacies (37.72\%) were dispensing Anti-TB drugs. The majority (37.04\%) of the community pharmacies were expecting to dispense Anti-TB drugs for 2 to 3 tuberculosis patients monthly. Community pharmacies located near Government civil hospital, 108 to 137 tuberculosis patients seeking Anti-TB drugs monthly. 53 community pharmacies (61.62\%) dispensing Anti-TB drugs through Private Physicians prescriptions. Conclusion: Tuberculosis patients are neglecting where Re-
\end{abstract}

vised National Tuberculosis Control Programme (RNTCP) facility for free treatment are available. Violation of the guidelines and regulations of dispensing Anti-TB potentially contribute to emergence of drug- resistant Mycobacterium tuberculosis. The community pharmacist should be encouraged to participate Directly observed treatment, short course (DOTS) program through RNTCP training.

Key words: Community Pharmacies, RNTCP, DOTS, Tuberculosis, Anti-TB drugs.

\section{Correspondence}

Dr. Uday Kumar Rangaswamy,

Research Scholar, Department of Pharmacy Practice, KLE College of Pharmacy, KLE Academy of Higher education and Research, Belagavi-590010, Karnataka, INDIA.

Phone: +91-9686873535

Email: uk96868735352@gmail.com

DOI: 10.5530/jyp.2019.11.60

\section{INTRODUCTION}

Tuberculosis is a major global public health challenge. ${ }^{1}$ Over a quarter of recorded deaths were reported from India, which carries the largest burden of the disease, with increasingly high rates of MDR-TB. Early symptoms of pulmonary TB are vague and persistent, leading infected individuals to seek care from a variety of local primary care providers. ${ }^{2}$ The Revised National Tuberculosis Control Program (RNTCP) under the auspices of the Ministry of Health and Family Welfare (MoHFW) of the Government of India had the mandate of prevention and care of TB in the country, including dispensing of medicines through the existing network of government health services. This network included facilities at state, district- and primary-levels, providing TB medicines free of cost. The Central TB Division of the MoHFW is the federal authority responsible for administering the RNTCP at the Centre. The RNTCP officially promulgated the policy of Directly Observed Therapy Short-Course (DOTS), the WHO-recommended global strategy for TB control, in all government facilities and in affiliated private facilities. Whereas a general lack of counseling and support of treatment adherence hampers successful, relapse-free cure. ${ }^{3}$ Moreover, most cases treated in the private sector are never notified to public health authorities. ${ }^{4}$ Estimating the numbers of patients being treated in the private sector is important since it provides information about the performance of a public system in detecting tuberculosis cases and also helps in planning for government intervention in the private sector. ${ }^{5}$ Hence, it is crucial to assess the scale of the problem. This crucially includes the undetected burden that exists outside the public health domain. ${ }^{6} \mathrm{~A}$ study of patient behavior from 13 countries reported that approximately $60 \%$ of TB patients begin their care seeking in the private or informal sectors, including pharma- cies. ${ }^{7}$ Pharmacies are highly accessible in India due to their vast numbers (around 800,000 nationally). ${ }^{8}$ long opening hours and absence of user fees. For many patients, pharmacies may be their first point of contact, where most drugs, including antibiotics, can be purchased Over-thecounter (OTC). ${ }^{9}$ Management of the patients was benchmarked against guidelines for pharmacists from the Government of India and the Indian Pharmaceutical Association. ${ }^{10}$ In this study, we evaluate the dispensing pattern and practices of community pharmacies towards antituberculosis drugs to understand the current trend of Pharmacy practice.

\section{MATERIALS AND METHODS}

The study was conducted at Belagavi city, Karnataka, India on 228 pharmaceutical outlets. A structured interview form was used to assess availability and non-availability of Anti-TB drugs, Community pharmacist dispensing pattern of Anti-TB drugs in weekly and monthly basis. In person interviews were administered after obtaining a written consent.

\section{Ethical Considerations}

This project was approved by KLE University Ethics committee on human subjects, KLE Academy of higher education and research, deemed to be university, Belagavi, Karnataka state, India, (Ref No. KAHER/ Ethics/2018-19/D-129). Survey consent was taken from each community pharmacist of the shop about the study participants, voluntary involvement and confidentiality. The community pharmacists were asked to sign and seal/stamp in both survey consent form and structured questionnaires. 


\section{Study Design and Study Settings}

A Cross sectional study was conducted in Belagavi city, Karnataka state, India, during June 2018 to April 2019. All the registered pharmaceutical outlets in Belagavi district were included for the study. Pharmacies dealing as wholesale distributors or attached with hospital were excluded from the study. Community pharmacist information leaflet were distributed in regional language Kannada and English. The community pharmacist information leaflet includes the study objectives, role of community pharmacist in tuberculosis control and care, burden of tuberculosis in India and in district.

\section{Study Setting and Participants}

The study was implemented in Belagavi, Karnataka, India with a population of approximately 5 lakhs residents. The study population encompassed registered community pharmacy outlets.

\section{Date Collection and Data Analysis}

The survey included the community pharmacy details. All the data obtained was tabulated using Microsoft Excel (Microsoft Corporation, CA, USA). Descriptive Statistics was performed for all the data collected using the R statistics package 3.5.2 (R Project for statistical computing, Vienna, Austria).

\section{Study Sample Selection}

A total of 228 Pharmacy shops were surveyed. Drug distributors, nonavailability of qualified pharmacist on the time of survey, In-house hospital pharmacy shops are excluded from the study. Only qualified pharmacist or registered pharmacist at the time of survey has been included in the study (Figure 1).

\section{Instruments and Instrumentation}

A self-designed questionnaire was pre-tested through piloting among 20 randomly selected pharmacies, including those located in urban areas. Pilot questionnaire feedback was used to modify for educational background and dispensing practices regarding dispensing pattern of Anti-

Table 1: Details of Distribution of Gender Pharmacist, Community Pharmacies and Qualification of community pharmacist.

\begin{tabular}{ccc}
\hline $\begin{array}{c}\text { Details of community } \\
\text { Pharmacies }\end{array}$ & Number & $\%$ \\
\hline Gender Distribution & 206 & 90.35 \\
Male & 22 & 9.65 \\
Female & 228 & 100 \\
Total & & \\
Others & 180 & 78.95 \\
$\begin{array}{c}\text { Drug Distributors/ Wholesale } \\
\text { shop }\end{array}$ & 80 & 35.09 \\
Non availability of Qualified \\
$\begin{array}{c}\text { Pharmacist } \\
\text { In-house hospital Pharmacies } \\
\text { Qualifications }\end{array}$ \\
B. Pharm \\
D. Pharm \\
with other degree & 15 & 6.58 \\
M. Pharm & 12 & 5.26 \\
Total & 3 & 86.84 \\
D. Pharm & $\mathbf{2 2 8}$ & 6.58 \\
\hline
\end{tabular}

TB drugs. The modified questionnaire were distributed to the sample population. This study was carried out during pharmacy working $\mathrm{h}$ and the study was conducted under the close supervision of the researcher.

\section{RESULTS}

A total of 228 community pharmacists participated in the survey by providing answers to all relevant questions. Of these, 204 community pharmacists $(90.35 \%)$ were male and 22 community pharmacists $(9.65 \%)$ were female. The majority of 198 community pharmacist (86.84\%)possessed a Diploma in Pharmacy (D. Pharm) followed by 12 community pharmacist (5.26 \%) with Bachelor of Pharmacy (B. Pharm) degree, 3 community pharmacist (1.32\%) with Master of Pharmacy (M. Pharm) which is summarized in (Table 1 ).

86 community pharmacies (37.72\%) were dispensing Anti-TB drugs, 131 community pharmacies reported (57.46\%) non availability of AntiTB drugs, 9 community pharmacies (3.94\%) reported having dispensed Anti-TB drugs but stopped because of non-availability of tuberculosis patients and 2 community pharmacies $(0.88 \%)$ had stopped dispensing of Anti-TB drugs and the tuberculosis patients were notified to District RNTCP by community pharmacist (Figure 2 ).

54 community pharmacies were expecting 136 to 181 tuberculosis patients to purchase Anti-TB drugs in a month. The majority (37.04\%) of the community pharmacies dispensing 2 to 3 tuberculosis Patients Anti-Tb drugs monthly. We observed that seven (12.96\%) community pharmacies were located in proximity to Government civil hospital, which estimated 108 to 137 tuberculosis patients seeking Anti-TB drugs monthly (Table 2). Six community pharmacies were expecting 35 to 57 tuberculosis patients to purchase Anti-TB drugs per week. Two community pharmacies dispensing Anti-TB drugs (33.33\%), which received 2 to 3 tuberculosis patients per week (Table 3 ). Four community Pharmacies (66.67\%) were dispensing anti-TB drugs, which received 33 to 54 tuberculosis patients per week. Remaining 26 community pharmacist did not provide an estimate for the number of tuberculosis patients at the time of interview.

\section{Table 2: Community Pharmacist dispensing Anti-TB drugs on monthly} basis.

\begin{tabular}{cccc}
\hline Sl. No & $\begin{array}{c}\text { Number of Tuberculosis } \\
\text { patients }\end{array}$ & $\begin{array}{c}\text { Number of } \\
\text { Community } \\
\text { Pharmacies }\end{array}$ & $\%$ \\
\hline 1 & 1 t o2 Patients & 8 & 14.81 \\
2 & 2 to 3 Patients & 20 & 37.04 \\
3 & 3 to 4 Patients & 7 & 12.96 \\
4 & 3 to 5 Patients & 2 & 3.70 \\
5 & 4 to 5 Patients & 4 & 7.41 \\
6 & 5 to 10 Patients & 3 & 5.56 \\
7 & 10 to 15 Patients & 3 & 5.56 \\
8 & 10 to 20 Patients & 1 & \\
9 & 15 to 20 Patients & 1 & \\
10 & 20 to 25 Patients & 1 & 12.96 \\
11 & 50 to 55 Patients & 1 & $\mathbf{1 0 0 . 0 0}$ \\
12 & 5 to 6 Patients & 1 & \\
13 & 6 to 7 Patients & 1 & \\
14 & 2 to 4 Patients & 1 & $\mathbf{5 4}$ \\
Total & $\mathbf{1 3 6}$ to 181 Patients & & \\
\hline
\end{tabular}


Table 3: Community Pharmacist dispensing Anti-TB drugs on weekly basis.

\begin{tabular}{cccc}
\hline SI. No & $\begin{array}{c}\text { Number of Tuberculosis } \\
\text { patients }\end{array}$ & $\begin{array}{c}\text { Number of } \\
\text { Community } \\
\text { Pharmacies }\end{array}$ & $\%$ \\
\hline 1 & 2-3 Patients & 2 & 33.33 \\
2 & 3-4 Patients & 1 & \\
3 & 5-10 Patients & 1 & \\
4 & 10-20 Patients & 1 & 66.67 \\
5 & 15-20 Patients & 1 & $\mathbf{1 0 0 . 0 0}$ \\
\hline
\end{tabular}

Remaining 26 Community Pharmacist have no idea of dispensing Anti-TB drugs.

Table 4: Dispensing pattern of Anti-TB drugs.

\begin{tabular}{ccc}
\hline Dispensing Pattern of Anti-TB drugs & No. & $\%$ \\
\hline Government Physician & 5 & 5.82 \\
Private Physician & 53 & 61.62 \\
Both Government Physician and private & 8 & 9.30 \\
$\quad$ Physician & & \\
No idea on dispensing pattern & 20 & 23.26 \\
Total & $\mathbf{8 6}$ & $\mathbf{1 0 0 . 0 0}$ \\
\hline
\end{tabular}

We observed an interesting dispensing pattern of Anti-TB drugs 53 community pharmacist were (61.62\%) dispensing Anti-TB drugs based on prescription of Private Physicians. 5 community pharmacies (5.82\%) dispensing Anti-TB drugs based on prescription of Government Physicians. 8 Community pharmacies (9.30\%) were dispensing Anti-TB drugs through both Private and Government physicians, remaining 20 community Pharmacies (23.26\%) had no idea of dispensing pattern of Anti-TB drugs. (Table 4)

\section{DISCUSSION}

The study assumes significance by the principle that DOTS service through RNTCP for TB is made available to the public by the Government free of charge, which includes free diagnostics and nutritional supports to the patients. This is particularly important as India is aiming to achieve 'Universal Access' for quality assured diagnosis and treatment under RNTCP. ${ }^{11}$ Further, the emergence of multi-drug resistant TB is posing a serious threat to the effective control of the disease in India. In this context, community pharmacies have a big role to play.

In summary, this study assessed 228 community pharmacies for their availability and dispensing pattern of Anti-TB drugs. It was observed that $37.52 \%$ of the community pharmacies were dispensing Anti-TB drugs. This indicates that TB patients are not sufficiently aware of the free treatment provided by the RNTCP and are hence relying on drugs available through community pharmacies. This reflects on the financial burden that the TB patient bears when purchasing drugs from community pharmacies thereby contributing to a major reason for the discontinuation of treatment of TB patients, before the full course of treatment

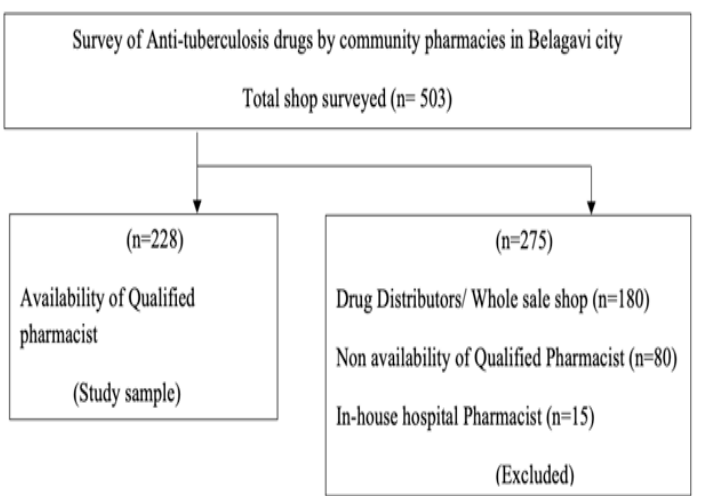

Figure 1: Sample Size selection across Belagavi city.

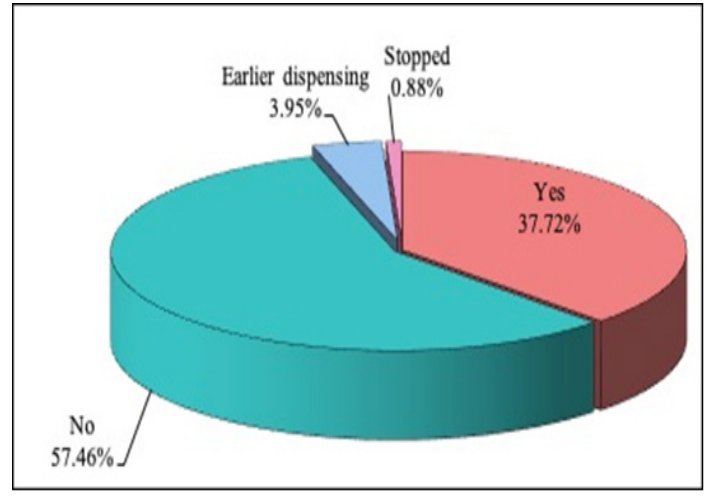

Figure 2: Availability and non-availability of Anti-TB drugs.

regimen is completed, as major community pharmacies do not maintain fallow up records. It may lead to drug- resistant TB. This understanding is significantly relevant in context with the Indian Pharmaceutical Association (IPA) continued efforts to integrate community pharmacies with the RNTCP-DOTS program. Prohibiting the guidelines and regulations of dispensing of antibiotics, including Anti-TB medicines, without prescription should be enforced to prevent further development of drugresistance TB.

Community pharmacists have not been engaged in national policy discussions around TB control. However, recent years have seen some progress in this area culminating in the memorandum of understanding between the Central TB Division and the Indian Pharmaceutical Association, the All India Organization of Chemists and Druggists, the Pharmacy Council of India and the SEAR Pharm forum to "engage pharmacist's in RNTCP for TB Care and Control in India”. Over the past decade, there have been projects focused on engaging pharmacists in India. ${ }^{10}$ But such Public-Private Mix (PPM) partnerships are yet to reach desired scale. ${ }^{12}$

\section{CONCLUSION}

The efforts of the RNTCP the DOTS programs can be effective only if the private sector stakeholders, especially community pharmacies, are involved in the National Strategic Plan (NSP) 2017 - 2025 to achieve a rapid decline in the burden of $\mathrm{TB}$, mortality and morbidity, while working towards the elimination of TB in India by 2025. Furthermore, the public and tuberculosis patients should be made more aware of the free DOTS treatment facility provided by RNTCP. 


\section{ACKNOWLEDGEMENT}

We would like to acknowledge VC, KAHER for allowing me to carry out the study. Authors also acknowledge community pharmacists who are involved in this study.

\section{CONFLICT OF INTEREST}

The authors declare no conflict of interest.

\section{ABBREVIATIONS}

TB: Tuberculosis; MDR-TB: Multidrug-resistant Tuberculosis; WHO: World Health Organization; RNTCP: Revised national tuberculosis control program; DOTS: Directly Observed Treatment, Short Course; MoHFW: Ministry of Health and Family Welfare; OTC: Over the counter; IPA: Indian Pharmaceutical Association; PPM: Public Private Mix; NSP: National Strategic Plan.

\section{REFERENCES}

1. Organisation WH. Global tuberculosis report. 2018 [Available from: https:// www.who.int/tb/publications/global_report/en/.]

2. Kapoor SK, Raman AV, Sachdeva KS, Satyanarayana S. How did the TB patients reach DOTS services in Delhi?. A study of patient treatment seeking behavior.
PLoS One. 2012;7(8):e42458.

3. Udwadia ZF, Pinto LM, Uplekar MW. Tuberculosis management by private practitioners in Mumbai, India: Has anything changed in two decades?. PLoS One. 2010;5(8):e12023.

4. Herbert N, George A, Baroness MI, Sharma V, Oliver M, Oxley A, et al. World TB Day 2014: Finding the missing 3 million. Lancet. 2014;383(9922): 1016-8.

5. Pai M, Dewan P. Testing and treating the missing millions with tuberculosis. PLoS Med. 2015;12(3):e1001805.

6. Cowling K, Dandona R, Dandona L. Improving the estimation of the tuberculosis burden in India. Bull World Health Organ. 2014;92(11):817-25.

7. Chin DP, Hanson CL. Finding the Missing Tuberculosis Patients. J Infect Dis. 2017;216(suppl_7):S675-8.

8. Miller R, Das J, Pai M. Quality of tuberculosis care by Indian pharmacies: Mystery clients offer new insights. Journal of Clinical Tuberculosis and Other Mycobacterial Diseases. 2018:10:6-8.

9. Smith $F$. The quality of private pharmacy services in low and middle-income countries: A systematic review. Pharm World Sci. 2009;31(3):351-61.

10. IPA. Revised National Tuberculosis Control Programme-Training Module For Community Pharmacists: Central TB Division, Directorate General of Health Services, Ministry of Health and Family Welfare. 2013. [Available from: http:/ www.pci.nic.in/Circulars/Training\%20Module.pdf ]

11. World Health Organisation. Universal Access to TB Care- Concurrence Report: Ministry of Health and family Welfare- Government of India. 2016. [Available from: http://www.searo.who.int/india/publications/universal_access to tb care_part1.pdf ]

12. Partnership LMT. Enrolling community pharmacists in a national tuberculosis control initiative. 2014. [Available from: https://s3.amazonaws.com/lillypad-us/ WP/wp-content/uploads/Creating-Champions-of-Change.pdf ]

Article History: Submission Date : 03-06-2019; Revised Date : 18-06-2019; Acceptance Date : 08-07-2019.

Cite this article: Rangaswamy UK, Ganachari MS. Evaluation of Community Pharmacies Dispensing Pattern and Practice of Antituberculosis Drugs in North Karnataka Region. J Young Pharm. 2019;11(3):300-3. 